\title{
RESONANCE AND TIME-OF-FLIGHT METHODS FOR EVALUATING THE MODULUS OF ELASTICITY OF PARTICLEBOARDS AT DIFFERENT HUMID CONDITIONS
}

\author{
Sheikh Ali Ahmed, Stergios Adamopoulos, Francesco Poggi \\ LinNaEus University \\ SwEDEN \\ Thomas Walther \\ IKEA Industry AB \\ SWEDEN \\ (Received May 20I9)
}

\begin{abstract}
Non-destructive testing of wood panels by either resonance or time-of-flight (TOF) methods provides possibilities for predicting their static bending properties. In the present study, three non-destructive devices (BING - Beam Identification by Non-destructive Grading by CIRAD, Montpellier, France, Fakopp Ultrasonic Timer and Sylvatest TRIO) were used for measuring the dynamic stiffness of different particleboard types. Fakopp Ultrasonic Timer and Sylvatest TRIO produce ultrasonic pulses to measure the sound velocity while BING uses resonance frequencies. Commercially produced particleboards with different thickness and densities were used to measure the dynamic modulus of elasticity $\left(M O E_{d y n}\right)$ in two directions (parallel and perpendicular to the production line) and at three different humidity levels (dry - 35\%, standard - $65 \%$ and wet $-85 \% \mathrm{RH}$ in constant temperature of $20^{\circ} \mathrm{C}$ ). $M O E_{d y n}$ of particleboards were correlated with the static moduli of elasticity $\left(M O E_{\text {stat }}\right)$ and rupture $\left(M O R_{\text {stat }}\right)$. It was found that the non-destructive methods gave higher $M O E_{d y n}$ values in both production directions than that of $M O E_{\text {stat }}$ values. $M O E_{d y n}$ was found to decrease from dry to wet conditions. A very strong and statistically significant correlation existed between $M O E_{d y n}$ and static bending properties. $M O E_{d y n}$ correlated stronger to $M O E_{\text {stat }}$ than $M O R_{\text {stat }}$. At different humidity level, all three methods- Fakopp Ultrasonic Timer, BING and Sylvatest TRIO analyses showed good predicting capabilities to estimate $M O E_{\text {stat }}$ and $M O R_{\text {stat }}$ of different particleboard types with high level of accuracy.
\end{abstract}

KEYWORDS: Ultrasonic velocity, vibration methods, static bending, dynamic modulus of elasticity, wood panels. 


\section{INTRODUCTION}

Wood panels are widely used in furniture manufacturing and for construction purposes. In wood-based panel industry, the main goal is to produce panels with high and consistent quality. An understanding of the fundamental mechanical properties is needed in order to specify their particular applications. One of the properties is modulus of elasticity (MOE), which describes the material's stiffness and it is a key indicator used for evaluating the mechanical properties of wood panels. A high value of MOE indicates a high resistance of the material to deformation (Liang and Fu 2007). To determine the stiffness and strength properties of materials, small samples are destructively tested in a testing machine according to standard methods. This type of evaluation process is time-consuming, expensive and more importantly destructive in nature. Thus, special attention was given on different types of non-destructive tests, and mainly acoustic methods have been applied within the last decade for standing trees (Tsehaye et al. 2000a, Amishev and Murphy 2008, Lindström et al. 2009, Wang 2013), logs (Jang 2000, Tsehaye et al. 2000b, Matheson et al. 2002, Dickson et al. 2004, Edlund et al. 2006), lumber (Brancheriau and Baillères 2003, Baltrušaitis and Mišeikytė 2011, Øvrum 2013). On the contrary, little attention has been paid on the non-destructive evaluation of wood panels (Dunlop 1980, Bekhta and Marutzky 2007, Niemz and Mannes 2012, Guan et al. 2015).

Usually, non-destructive testing is carried out by using two acoustic methods; the time-offlight (TOF) and the resonance method. TOF relies on the evaluation of propagation time of a pulse of ultrasound or a stress wave across the material while the resonance method is based on the free vibration frequency of the material under forced harmonic vibration. The resonance method provides more information on the elastic properties of materials and it is more reliable than the TOF method. Most of the resonance-based acoustic tools have a built-in fast Fourier transformation program that can analyze the acoustic signals. The dynamic modulus of elasticity $\left(M O E_{d y n}\right)$ is obtained from the acoustic velocity or the resonance frequency data. It is reported that the ultrasonic pulse transit time gives the highest $M O E_{d y n}$, which is followed by the stress wave transit time, and then the longitudinal and flexural vibration frequency (Hassan et al. 2013, Wang 2013, Chauhan and Sethy 2016, Legg and Bradley 2016). Acoustic tools based on the two non-destructive methods have proved to provide a rapid, reliable and simple measure of $M O E_{d y n}$ for trees, logs, lumber and wood-based panels, and have also shown good potential to predict their static bending properties (static moduli of elasticity $M O E_{\text {stat }}$ and rupture $M O R_{\text {stat }}$ ).

Several researchers have compared $M O E_{d y n}$ or acoustic wave velocity with $M O E_{\text {stat }}$ or $M O R_{\text {stat }}$ of wood panels, and have reported good to strong association between them (Ross and Pellerin 1988, Han et al. 2006, Guan et al. 2015). However, values of $M O E_{d y n}$ varied depending on the method used. Moreover, moisture has an influence on the sound wave and resonance properties of wood panels as they can swell considerably in humid conditions. However, moisture influence is more predictable for solid wood than wood panels. As for example, the stress wave velocity in solid wood is affected by about $1 \%$ per percent of $\mathrm{MC}$ change in the hygroscopic range (Han et al. 2006). However, such linear relationship is not observed in wood panels due their complex nature and large thickness swelling in humid conditions and thus are less predictable in higher moisture range.

Swelling of wood panels is complicated as it is often accompanied with internal bond failures that lead to changes of their internal structure (Wu and Piao 1999). It is thus needed to establish correlations between the acoustic properties and stiffness/strength of wood panels in different humid conditions, which will enable more safe predictions of their behavior in the intended end uses. Temperature also influences the bending strength and stiffness of wood-based panels 
(Bekhta and Marutzky 2007), so it should be taken into account for a proper non-destructive evaluation by acoustics. Several other factors need to be considered in non-destructive testing of wood panels, such as the size, shape and variability of the particles, the spatial variation in orientation, the distribution of binder and additives, the size, shape and variation of cavities, and the layering and density variation through the panel thickness (Bodig 2000). Since wood panels are multiphase products, intensive care should be taken in selecting the proper non-destructive method for a specific panel type that more closely responds to the controlling variables of interest (e.g. wave velocity, $M O E_{d y n}$, shear modulus).

Application of non-destructive acoustic testing for wood-based panels is still in infancy but could be very useful in contemporary quality control of the production for fast determinations of stiffness and strength properties of different panel types. The main objective of this paper was to evaluate the potential of three acoustic tools based on TOF and resonance methods for assessing the mechanical performance (static bending properties) of commercially produced particleboards as effected by their moisture content. Predictions of $M O E_{\text {stat }}$ and $M O R_{\text {stat }}$ of the particleboards exposed to three humid conditions (dry, standard and wet) were based on $M O E_{d y n}$ values determined by TOF and resonance methods.

\section{MATERIALS AND METHODS}

\section{Commercial wood panels}

Four (4) types of commercially produced particleboards with different binders, thicknesses and densities were used in this study. The particleboards were collected from factories in Slovakia, Sweden and Poland. Their details are presented in the following Tab. 1.

Tab. 1: Types of particleboards used in the study. Values in parenthesis are the standard deviation of density measured after conditioning at $20^{\circ} \mathrm{C}$ and $65 \% \mathrm{RH}$.

\begin{tabular}{|l|c|c|c|}
\hline \multicolumn{1}{|c|}{ Type of particleboard } & Type of glue used & Thickness $(\mathrm{mm})$ & Density $\left(\mathrm{g} \cdot \mathrm{cm}^{-3}\right)$ \\
\hline Standard particleboard (PB1) & UF & 16 & $0.60(0.03)$ \\
\hline High density particleboard (PB2) & UF & 20 & $0.72(0.01)$ \\
\hline Non-load bearing particle board (PB3) & pMDI & 19 & $0.66(0.00)$ \\
\hline Load bearing particle board (PB4) & pMDI & 19 & $0.69(0.01)$ \\
\hline
\end{tabular}

PB: particleboard; UF: urea formaldehyde; pMDI: polymeric diphenylmethane diisocyanate.

Three climatic conditions were considered for this study: dry $\left(20^{\circ} \mathrm{C}, 35 \% \mathrm{RH}\right)$, standard $\left(20^{\circ} \mathrm{C}, 65 \% \mathrm{RH}\right)$ and wet $\left(20^{\circ} \mathrm{C}, 85 \% \mathrm{RH}\right)$. Both static $\left(M O E_{\text {stat }}\right.$ and $\left.M O R_{\text {stat }}\right)$ and dynamic $M O E_{d y n}$ were measured in samples acclimatized at those three climatic conditions. The samples were considered to be acclimatized when the difference between two weightings within 24 hours were smaller than $0.1 \%$ mass of the sample. Moisture content MC (SS-EN 322) and density (SS-EN 323) of the samples were measured after acclimatization at dry, standard and wet conditions.

Two panel directions were considered for determining the bending (static and dynamic) properties viz. parallel and perpendicular. Two different directions, three climatic conditions and six replications produced a total of 36 samples for each board type (see Tab. 2). 
Tab. 2: Dimensions (length $\times$ width $\times$ thickness) and number of samples for different tests in three different climatic conditions.

\begin{tabular}{|c|c|c|c|}
\hline Board type & Direction & Dimension $(\mathbf{m m})$ & Number of samples \\
\hline PB1 & $\| \& \perp$ & $370 \times 50 \times 16$ & 36 \\
\hline PB2 & $\| \& \perp$ & $450 \times 50 \times 20$ & 36 \\
\hline PB3 & $\| \& \perp$ & $430 \times 50 \times 19$ & 36 \\
\hline PB4 & $\| \& \perp$ & $430 \times 50 \times 19$ & 36 \\
\hline
\end{tabular}

I: parallel direction; $\perp$ : perpendicular direction.

\section{Non-destructive testing}

Resonance method

For the resonance method, the BING system was used. This is a non-destructive testing device designed to evaluate the mechanical properties of rigid materials using vibration analysis (Brancheriau and Baillères 2002). Main element of the system is the measurement software $\mathrm{BING}^{\circledR}$ (version 9.6.2), which controls a data acquisition logger (PicoScope 4224, UK), processes data and delivers results. In this purpose, a free-free flexural vibration test setup was used (Fig. 1).

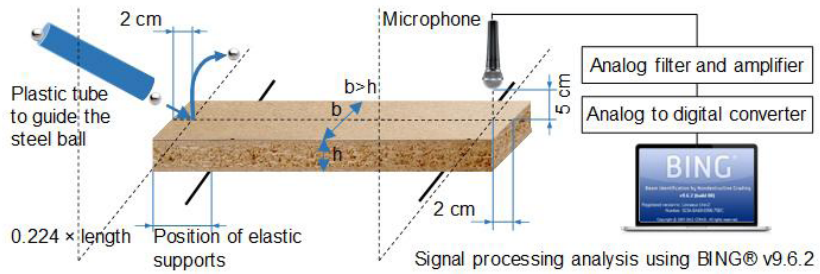

Fig. 1: Schematic representation of the experimental setup for measuring the vibrational properties of particleboards. Note: $b$ and $h$ are the width and height of the sample, respectively.

Each test piece was placed on two elastic supports on nodal points $(0.224 \times$ length $)$ from the both ends of the sample to allow free vibrations. A small stainless steel ball (diameter $14 \mathrm{~mm}$ and mass $11.2 \mathrm{~g}$ ) was dropped at one flat end to produce an exciting impulse. On the other end, an omnidirectional microphone was placed to measure the acoustic signal radiated by the impact. The signals were transmitted via PicoScope, and acoustic classification and signal-processing analysis was performed by the $\mathrm{BING}^{\circledR}$ software at a signal sampling frequency of $40000 \mathrm{~Hz}$ and with a spectral acquisition of 16384 points.

The first four modes of vibration were used for determining the dynamic modulus of elasticity $\left(M O E_{d y n}\right)$. More details about the motion equation and method can be found in Hein et al. (2012). The test was repeated four times for every sample with two times in each side and the average was calculated.

\section{Time-of-flight method}

Two different ultrasonic testing devices were used for the TOF method; Fakopp Ultrasonic Timer (Fakopp Enterprise Bt., Hungary) and Sylvatest TRIO (CBS-CBT, France). Both devices use a single pass measurement of time and involve two transducers (sender and receiver) connected to the testing equipment with cables. The devices create ultrasonic excitation and then it is measured the time needed for the ultrasonic impulse to travel from one transducer to another. For Sylvatest TRIO, the result (ultrasonic propagation time) was the average of four impulses in 
a sequence. To get a more accurate result, three measurements were performed; two at the top and bottom surface layers and one at the core layer of the particleboard samples (Fig. 2). The average data of the three measurements were used for the calculation of velocity. For Fakopp Ultrasonic Timer, two special triangle-shaped piezoelectric sensors were placed on the flat sides of the samples. Measurements of the propagation time were performed on both the top and bottom surfaces of the samples and the average data was used for the calculation of the ultrasonic wave velocity (Fig. 2).

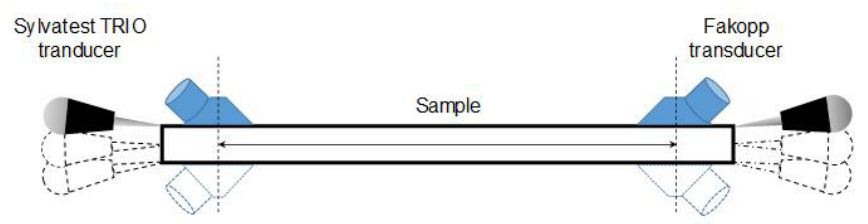

Fig. 2: Measurement of ultrasonic wave velocity on different positions of the particleboard sample by Sylvatest TRIO and Fakopp Ultrasonic Timer.

The acoustic velocity for each sample was calculated using the following formula:

$$
V=\frac{D}{T} \times 1000
$$

where: $\mathrm{V}$ is the ultrasonic velocity $\left(\mathrm{m} \cdot \mathrm{s}^{-1}\right), \mathrm{D}$ is the distance of the transducers $(\mathrm{mm})$ and $\mathrm{T}$ is the time needs to travel from the sender to the receiver transducer $(\mu \mathrm{s})$. Then, $\mathrm{V}\left(\mathrm{m} \cdot \mathrm{s}^{-1}\right)$ and density $\rho\left(\mathrm{g} \cdot \mathrm{cm}^{-3}\right)$ were used to calculate the $M O E_{d y n}(\mathrm{MPa})$ with the following formula:

$$
M O E_{d y n}=\rho V^{2}
$$

\section{Static bending test}

A universal testing machine (MTS 810, MTS System Corporation, USA) was used for the three-point bending test following the standard SS-EN 310. Uniaxial load was applied on the flat side of the samples. The loading rate was adjusted so that the maximum load was reached within $60 \pm 30 \mathrm{~s}$. During the bending test, the deflection and load were recorded until the fracture of the sample. From the load-deflection curve, the modulus of elasticity $\left(M O E_{\text {stat }}\right)$ and modulus of rupture $\left(M O R_{\text {stat }}\right)$ were calculated.

\section{Data analysis}

The $M O E_{d y n}$ data of different samples in three climatic conditions were analyzed using the statistical software package IBM SPSS Statistics, Version 23 (IBM Corporation, New York, USA). One-way analysis of variance (ANOVA) was applied to determine whether $M O E_{d y n}$ were significantly different among the sample categories. A 5\% level of significance was used to detect differences and when a significant difference was found, Duncan's multiple-range test was performed. To measure the significance of relationships among the static and dynamic data, regression analysis was performed at 95\% confidence level using Microsoft Excel 2016 program (Microsoft, Redmond, WA, USA). 


\section{RESULTS AND DISCUSSION}

\section{Static bending}

$M O E_{\text {stat }}$ and $M O R_{\text {stat }}$ are important properties that measure respectively the elastic behavior and resistance to bending when the particleboard is under static load. Therefore, these properties determine largely the applicability of particleboards as structural components in furniture and other constructions. Tab. 3 summarizes the moisture content, density, static bending $M O E_{\text {stat }}$ and $M O R_{\text {stat }}$ in both parallel and perpendicular of particleboard's production line at the three selected humid conditions.

Tab. 3: Equilibrium moisture content (EMC), density, static bending strength $\left(M O R_{\text {stat }}\right)$ and stiffness $\left(M O E_{\text {stat }}\right)$ of the particleboard types after conditioning in three different humid conditions at constant temperature $20^{\circ} \mathrm{C}$. Values in parenthesis are the standard deviations.

\begin{tabular}{|c|c|c|c|c|c|c|c|c|c|c|c|c|c|}
\hline \multirow{2}{*}{\multicolumn{2}{|c|}{$\begin{array}{l}\text { Board } \\
\text { type }\end{array}$}} & \multicolumn{4}{|c|}{ Dry, 35\% RH } & \multicolumn{4}{|c|}{ Standard, 65\% RH } & \multicolumn{4}{|c|}{ Wet, 85\% RH } \\
\hline & & $\begin{array}{c}E M C \\
(\%) \\
\end{array}$ & $\begin{array}{l}\text { Density } \\
\left(\mathrm{g} \cdot \mathrm{cm}^{-3}\right)\end{array}$ & $\begin{array}{c}M O E_{\text {stat }} \\
(\mathrm{MPa})\end{array}$ & $\begin{array}{c}M O R_{\text {stat }} \\
(\mathrm{MPa})\end{array}$ & $\begin{array}{c}E M C \\
(\%) \\
\end{array}$ & $\begin{array}{l}\text { Density } \\
\left(\mathrm{g} \cdot \mathrm{cm}^{-3}\right)\end{array}$ & $\begin{array}{c}M O E_{\text {stat }} \\
(\mathrm{MPa})\end{array}$ & $\begin{array}{c}M O R_{\text {stat }} \\
(\mathrm{MPa})\end{array}$ & $\begin{array}{c}E M C \\
(\%) \\
\end{array}$ & $\begin{array}{l}\text { Density } \\
\left(\mathrm{g} \cdot \mathrm{cm}^{-3}\right) \\
\end{array}$ & $\begin{array}{c}M O E_{\text {stat }} \\
(\mathrm{MPa})\end{array}$ & $\begin{array}{c}M O R_{\text {stat }} \\
(\mathrm{MPa})\end{array}$ \\
\hline \multirow{4}{*}{ PB1 } & & & 0.60 & 2891 & 11.36 & \multirow{4}{*}{$\begin{array}{c}9.9 \\
(0.04)\end{array}$} & 0.60 & 2421 & 10.91 & \multirow{4}{*}{$\begin{array}{l}14.0 \\
(0.12)\end{array}$} & 0.60 & 1871 & 8.89 \\
\hline & 11 & 6.7 & $(0.03)$ & (225) & (1.04) & & $(0.03)$ & (233) & (1.37) & & $(0.02)$ & (157) & $(0.84)$ \\
\hline & \multirow{2}{*}{$\perp$} & $(0.01)$ & 0.59 & 2381 & 10.35 & & 0.60 & 2067 & 9.61 & & 0.61 & 1498 & 7.69 \\
\hline & & & $(0.00)$ & (167) & $(1.17)$ & & $(0.00)$ & $(110)$ & $(0.97)$ & & $(0.01)$ & (235) & $(0.95)$ \\
\hline \multirow{4}{*}{ PB2 } & & \multirow{4}{*}{$\begin{array}{c}7.1 \\
(0.03)\end{array}$} & 0.72 & 3943 & 19.61 & \multirow{4}{*}{$\begin{array}{c}9.7 \\
(0.02)\end{array}$} & 0.73 & 3503 & 19.25 & \multirow{4}{*}{$\begin{array}{c}13.3 \\
(0.26)\end{array}$} & 0.73 & 2812 & 17.04 \\
\hline & . & & $(0.01)$ & (110) & $(1.31)$ & & $(0.01)$ & $(103)$ & $(0.90)$ & & $(0.01)$ & (71) & $(0.82)$ \\
\hline & I & & 0.72 & 3788 & 19.19 & & 0.72 & 3319 & 18.29 & & 0.73 & 2675 & 16.11 \\
\hline & $\perp$ & & $(0.01)$ & (41) & $(0.48)$ & & $(0.01)$ & (29) & $(0.71)$ & & $(0.01)$ & (31) & $(0.36)$ \\
\hline \multirow{4}{*}{ PB3 } & H & \multirow{4}{*}{$\begin{array}{c}7.2 \\
(0.02)\end{array}$} & 0.65 & 2657 & 12.51 & \multirow{4}{*}{$\begin{array}{c}10.2 \\
(0.05)\end{array}$} & 0.65 & 2324 & 12.04 & \multirow{4}{*}{$\begin{array}{c}13.6 \\
(0.04)\end{array}$} & 0.66 & 1913 & 10.01 \\
\hline & $\|$ & & $(0.00)$ & (43) & (1.21) & & $(0.00)$ & (43) & $(0.70)$ & & $(0.00)$ & (42) & $(0.61)$ \\
\hline & 1 & & 0.65 & 2452 & 12.65 & & 0.65 & 2140 & 11.71 & & 0.66 & 1746 & 9.33 \\
\hline & $\perp$ & & $(0.01)$ & (101) & $(1.17)$ & & $(0.01)$ & (133) & $(0.66)$ & & $(0.01)$ & (51) & $(0.85)$ \\
\hline \multirow{4}{*}{ PB4 } & |l & \multirow{4}{*}{$\begin{array}{c}6.7 \\
(0.08)\end{array}$} & 0.69 & 2954 & 15.17 & \multirow{4}{*}{$\begin{array}{c}10.0 \\
(0.05)\end{array}$} & 0.70 & 2655 & 14.56 & \multirow{4}{*}{$\begin{array}{l}13.7 \\
(0.13)\end{array}$} & 0.70 & 2132 & 11.63 \\
\hline & & & $(0.01)$ & (112) & $(1.02)$ & & $(0.01)$ & $(166)$ & $(0.99)$ & & $(0.01)$ & (80) & $(0.57)$ \\
\hline & ] & & 0.68 & 2685 & 14.40 & & 0.70 & 2285 & 12.98 & & 0.70 & 1870 & 10.63 \\
\hline & $\perp$ & & $(0.03)$ & (54) & $(0.53)$ & & $(0.01)$ & (40) & $(0.71)$ & & $(0.01)$ & (32) & (0.98) \\
\hline
\end{tabular}

II: parallel direction; $\perp$ : perpendicular direction.

In all particleboards, static bending properties parallel to the production line showed higher values than perpendicular to the production line. As expected the high-density particleboard (PB2) had the highest values than the other types. At standard condition $\left(20^{\circ} \mathrm{C}\right.$ and $\left.65 \% \mathrm{RH}\right)$, $M O E_{\text {stat }}$ and $M O R_{\text {stat }}$ values for PB2 boards were $8-11 \%$ and $8-14 \%$ higher, respectively. With increasing humidity and consequently $\mathrm{MC}$ from the dry to the wet condition, the bending properties decreased for all types of particleboards. The reduction was more pronounced from the standard to wet condition. Similar humidity and MC effects were also found elsewhere for wood panels (Wu and Suchsland 1997, Pritchard 2001) as well as for wood (Gerhards 1982). Particleboards are formed under pressure and the adhesive holds the particles in a compressed state, which means that they are self-stressed in compression perpendicular to the grain of the wood fibers. MC changes lead to relaxation of stresses and recovery of the locked-in deformations resulting in increase of board dimensions and some change in the moment of inertia (Oliver 1981). In addition, the decrease of stiffness and strength is directly affected by the humidity changes but the magnitude depends on the type of adhesive. An experiment by Dinwoodie (1978) reported that urea-formaldehyde bonded boards subjected to humidity change from 30\% to $90 \%$ RH retained only $58 \%$ and $45 \%$ of their initial $M O R_{\text {stat }}$ and $M O E_{\text {stat }}$ respectively, whilst boards 
bonded with melamine urea-formaldehyde, phenol formaldehyde and sulphite liquor retained at least $73 \%$ and often more than $90 \%$ of their initial property value.

The reduction in strength properties is due to the effect of mechanical stressing set up by alternate swelling and shrinkage of adjacent particles (Halligan and Schniewind 1974, Dinwoodie 1978). Both $M O E_{\text {stat }}$ and $M O R_{\text {stat }}$ are affected by various processing parameters like the board density, surface density and particle size, particle alignment, moisture content, and particularly by the nature of adhesives used (Kollmann et al. 1975, Jian and Lu 2017). The higher $M O E_{\text {stat }}$ and $M O R_{\text {stat }}$ values observed in the parallel than in the perpendicular direction for all particleboard types in all humid conditions could be explained by the particle orientation in respect to the direction of the production line. Parallel to the production line, the orientation of particles with their fibers along the grain provide increased strength and stiffness to resist stress while loading of particles against the grain in the perpendicular direction results in lower flexure values (Han et al. 2006, Buyuksari 2012, Ayrilmis et al. 2010). In addition, the fine particles of the panel's face layers need the core layer as a strengthening element. Panels with core layer particles with parallel orientation affects and enables the core layer to resist it from deformation and failure when subjected to the bending loads (Benthien and Ohlmeyer 2018).
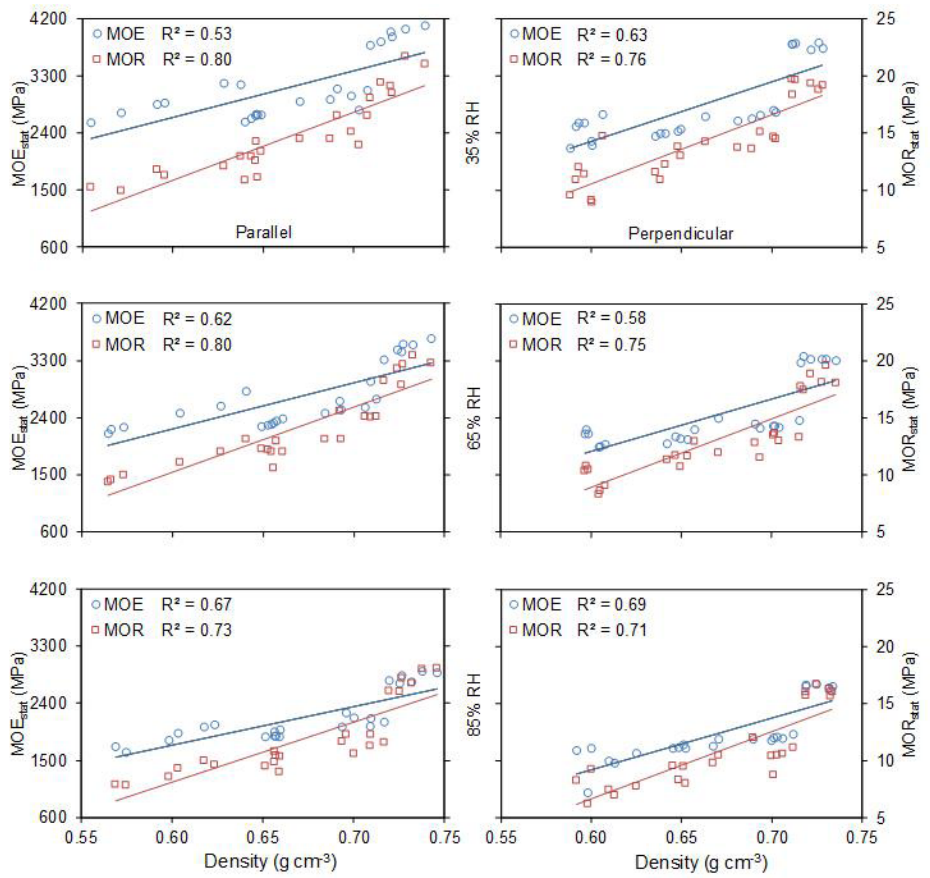

Fig. 3: Relationship of static bending properties $\left(M O E_{\text {stat }}, M O R_{\text {stat }}\right.$ ) with density for the particleboard types acclimatized at three humid conditions.

Fig. 3 shows the relationship of $M O E_{\text {stat }}$ and $M O R_{\text {stat }}$ with the density of all particleboard types at each humid condition. In every humid condition, linear regression models of $M O E_{\text {stat }}$ and $M O R_{\text {stat }}$ with the density showed significant positive relationships $(\mathrm{p}<0.05)$.

As revealed by the coefficients of determination, the relationship of density was stronger with $M O R_{\text {stat }}$ than with $M O E_{\text {stat }}$. Our findings are in agreement with previous studies (Wong 
et al. 1998, Rachtanapun et al. 2012, Guan et al. 2016), which reported an increase in $M O E_{\text {stat }}$ and $M O R_{\text {stat }}$ with increasing board density. The surface board density plays an important role on the $M O R_{\text {stat }}$ since bending stresses are higher at the surfaces. Furthermore, $M O R_{\text {stat }}$ values are highly dependent on the vertical density gradient where different values can be obtained for equal average board densities simply by changing the processing parameters (Wong et al. 1998).

However, in this study, the mean board density was used for analysis, and therefore no conclusions can be made on the effect of density gradient on the bending performance of the particleboard types. Linear regressions model was used to determine how well the $M O R_{\text {stat }}$ is related with $M O E_{\text {stat }}$ values in parallel and perpendicular samples (Fig. 4). It showed strong positive and significant relationships $(\mathrm{p}<0.05)$ for every humid condition, particleboard direction (parallel and perpendicular) as well as when all data were grouped together. Strong correlation between bending strength and modulus of elasticity is also reported for wood (Olsson et al. 2012, Baar et al. 2015) and wood-based panels (McNatt et al. 1990, Jian and Lu 2017).
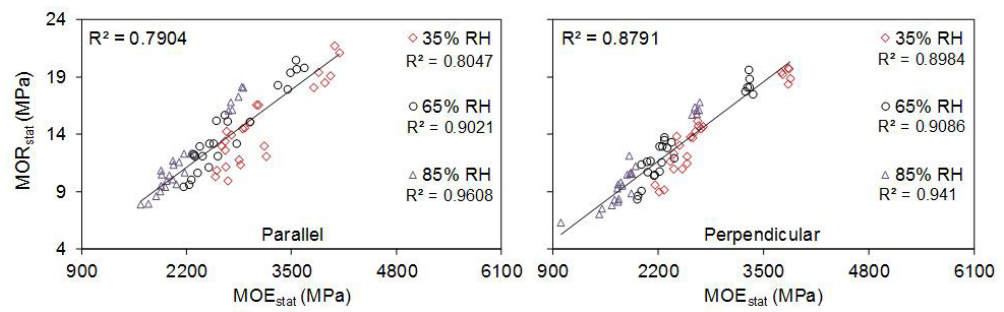

Fig. 4: Relationship of $M O E_{\text {stat }}$ and $M O R_{\text {stat }}$ for the particleboard types acclimatized at three humid conditions.

\section{Dynamic modulus of elasticity}

$M O E_{d y n}$ represents the mean stiffness value of a sample whilst $M O E_{\text {stat }}$ represents the local stiffness of the material at the highly stressed areas of a specific test setup. The $M O E_{d y n}$ values measured for the different particleboard types at dry, standard and wet conditions by the different resonance and TOF methods are presented in Tabs. 4-6.

Tab. 4: Dynamic modulus of elasticity $\left(M O E_{d y n}\right)$ of the particleboard types, after conditioning in three different humid conditions at constant temperature $20^{\circ} \mathrm{C}$, measured by BING in transversal vibration (resonance method). Values in parenthesis are the standard deviations.

\begin{tabular}{|c|c|c|c|c|}
\hline \multirow{2}{*}{ Board type } & \multirow{2}{*}{$\begin{array}{c}\text { Direction of } \\
\text { board }\end{array}$} & Dry, 35\% RH & Standard, $65 \% \mathrm{RH}$ & Wet, $85 \% \mathrm{RH}$ \\
\hline & & $M O E_{d y n}(\mathrm{MPa})$ & $M O E_{d y n}(\mathrm{MPa})$ & $M O E_{d y n}(\mathrm{MPa})$ \\
\hline \multirow{2}{*}{ PB1 } & $\|$ & 3631a (212) & $3376 \mathrm{a}(189)$ & 2683b (132) \\
\hline & $\perp$ & $3294 a(274)$ & $3048 a(242)$ & 2398b (195) \\
\hline \multirow{2}{*}{$\mathrm{PB} 2$} & $\|$ & $5754 \mathrm{a}(71)$ & 5408b (54) & $4461 c(62)$ \\
\hline & $\perp$ & 5301a (217) & $4980 \mathrm{a}(202)$ & 4102b (191) \\
\hline \multirow{2}{*}{ PB3 } & $\|$ & $3527 \mathrm{a}(142)$ & $3260 \mathrm{~b}(146)$ & 2721c (101) \\
\hline & $\perp$ & $3185 a(58)$ & $2945 b(39)$ & $2432 c(37)$ \\
\hline \multirow[t]{2}{*}{ PB4 } & $\|$ & $3808 \mathrm{a}(66)$ & $3428 \mathrm{~b}(58)$ & $2867 \mathrm{c}(28)$ \\
\hline & $\perp$ & $3615 \mathrm{a}(17)$ & 3250b (14) & $2689 \mathrm{c}(17)$ \\
\hline
\end{tabular}

II: parallel direction; $\perp$ : perpendicular direction.

Mean values followed by different letter within a row indicate that there is a significant difference $(\mathrm{p} \leq 0.05)$ as determined by ANOVA and Duncan's multiple range test. 
Vol. 65 (3): 2020

Tab. 5: Dynamic modulus of elasticity (MOE dyn of the particleboard types, after conditioning in three different humid conditions at constant temperature $20^{\circ} \mathrm{C}$, measured by Fakopp Ultrasonic Timer (TOF method). Values in parenthesis are the standard deviations.

\begin{tabular}{|c|c|c|c|c|}
\hline \multirow{2}{*}{ Board type } & \multirow{2}{*}{$\begin{array}{c}\text { Direction of } \\
\text { board }\end{array}$} & Dry, 35\% RH & Standard, 65\% RH & Wet, 85\% RH \\
\hline & & $M O E_{d y n}(\mathrm{MPa})$ & $M O E_{d y n}(\mathrm{MPa})$ & $M O E_{d y n}(\mathrm{MPa})$ \\
\hline \multirow{2}{*}{ PB1 } & $\|$ & $4184 \mathrm{a}(207)$ & $3944 a(174)$ & $3316 \mathrm{~b}(126)$ \\
\hline & $\perp$ & $3606 a(165)$ & $3276 \mathrm{~b}(163)$ & 2897c (144) \\
\hline \multirow{2}{*}{ PB2 } & $\|$ & $5822 \mathrm{a}(110)$ & $5617 \mathrm{~b}(103)$ & $4870 c(69)$ \\
\hline & $\perp$ & $5383 a(53)$ & $5327 \mathrm{a}(166)$ & 4505b (161) \\
\hline \multirow{2}{*}{ PB3 } & $\|$ & 3918a (132) & $3732 \mathrm{a}(127)$ & $3222 b(132)$ \\
\hline & $\perp$ & $3520 \mathrm{a}(61)$ & 3353b (98) & $2948 c(59)$ \\
\hline \multirow{2}{*}{ PB4 } & $\|$ & $4469 a(95)$ & $4102 \mathrm{~b}(78)$ & $3525 c(63)$ \\
\hline & $\perp$ & 4132a (39) & $3846 \mathrm{~b}(25)$ & $3307 \mathrm{c}(22)$ \\
\hline
\end{tabular}

II: parallel direction; $\perp$ : perpendicular direction.

Mean values followed by different letter within a row indicate that there is a significant difference $(\mathrm{p} \leq 0.05)$

as determined by ANOVA and Duncan's multiple range test.

Tab. 6: Dynamic modulus of elasticity ( $\left.M O E_{d y n}\right)$ of the particleboard types, after conditioning in three different humid conditions at constant temperature $20^{\circ} \mathrm{C}$, measured by Sylvatest TRIO (TOF method). Values in parenthesis are the standard deviations.

\begin{tabular}{|c|c|c|c|c|}
\hline \multirow{2}{*}{ Board type } & $\begin{array}{c}\text { Direction of } \\
\text { board }\end{array}$ & $35 \% \mathrm{RH}$ & $65 \% \mathrm{RH}$ & $85 \% \mathrm{RH}$ \\
\cline { 2 - 5 } & $\|$ & $M O E_{d y n}(\mathrm{MPa})$ & $M O E_{d y n}(\mathrm{MPa})$ & $M O E_{d y n}(\mathrm{MPa})$ \\
\hline \multirow{2}{*}{$\mathrm{PB} 1$} & $\perp$ & $3273 \mathrm{a}(200)$ & $3230 \mathrm{a}(179)$ & $2713 \mathrm{~b}(121)$ \\
\cline { 2 - 5 } & $\|$ & $4000 \mathrm{a}(195)$ & $2925 \mathrm{a}(162)$ & $2449 \mathrm{~b}(112)$ \\
\hline \multirow{2}{*}{ PB2 } & $\perp$ & $4556 \mathrm{a}(115)$ & $4905 \mathrm{a}(103)$ & $4251 \mathrm{~b}(102)$ \\
\cline { 2 - 5 } & $\|$ & $3400 \mathrm{a}(112)$ & $4604 \mathrm{a}(105)$ & $3987 \mathrm{~b}(128)$ \\
\hline \multirow{2}{*}{ PB3 } & $\perp$ & $2998 \mathrm{a}(51)$ & $2923 \mathrm{a}(161)$ & $2864 \mathrm{~b}(119)$ \\
\hline \multirow{2}{*}{ PB4 } & $\|$ & $3903 \mathrm{a}(167)$ & $3652 \mathrm{a}(119)$ & $2603 \mathrm{~b}(60)$ \\
\cline { 2 - 5 } & $\perp$ & $3647 \mathrm{a}(57)$ & $3416 \mathrm{~b}(52)$ & $3095 \mathrm{~b}(122)$ \\
\hline
\end{tabular}

I: parallel direction; $\perp$ : perpendicular direction.

Mean values followed by different letter within a row indicate that there is a significant difference $(\mathrm{p} \leq 0.05)$

as determined by ANOVA and Duncan's multiple range test.

As expected, the increase of humidity from dry to wet conditions resulted in decreased $M O E_{d y n}$ due to the elevated EMC of particleboards. The trend was noticed in each particleboard type for all the acoustic methods used (Tab. 4-6). At $85 \% \mathrm{RH}, M O E_{d y n}$ of the particleboard types determined by both the resonance and TOF methods was found significantly lower than that was in 35\% and 65\% RH (ANOVA and Duncan's multiple range test, $\mathrm{P} \leq 0.05$ ). $M O E_{d y n}$ in TOF methods is directly related to the acoustic velocity (see formula 2). Resonance frequency and ultrasonic velocity of wood panels decrease with an increase in moisture content, and thus proportionally influence the $M O E_{d y n}$ (Bucur 2006). A similar trend has also been reported for solid wood (Llana et al. 2014). This phenomenon can be explained by the hypothesis that at dryer state, molecular chains in the amorphous regions of the cell wall are unusually distorted with the presence of microvoids between the molecular chains resulting in lower internal friction, which corresponds to higher $M O E_{d y n}$. With increasing moisture content, water molecules are embedded 
in the microvoids and rearrange the distorted molecular chains. However, with further increase in moisture content, water acts as a plasticizer allowing additional molecular movement and the cohesive forces between molecules are decreased. That results in a higher internal friction leading to a decrease in $M O E_{d y n}$ (Akitsu et al. 1993).

Like $M O E_{\text {stat }}$, higher $M O E_{d y n}$ was observed in samples parallel to the production line than perpendicular (Tabs. 4-6). The reason behind this result is the highest resonance frequency and ultrasonic velocity parallel to the grain (Bucur 2006, Han et al. 2006). The higher values of $M O E_{d y n}$ parallel to the production line of particleboards meant that higher number of wood particles along the grain were aligned in this direction. When different methods were compared, the mean values of the $M O E_{d y n}$ based on flexural vibration and TOF methods (Tabs. 4-6) were higher than $M O E_{\text {stat }}$ (Tab. 3) for each particleboard type and humid condition. As average, BING, Fakopp Ultrasonic Timer and Sylvatest TRIO gave respective $M O E_{d y n}$ values 29\%, $37 \%$ and $27 \%$ higher than $M O E_{\text {stat }}$ values. Moduli of elasticity determined using speed of sound measurements are in general higher than values determined by static experiments (Bucur 2006, Niemz and Mannes 2012, Hassan et al. 2013, Guan et al. 2015, Chauhan and Sethy 2016). Like wood, the difference between $M O E_{d y n}$ and $M O E_{s t a t}$ is attributed to the viscoelastic behaviour and damping properties of particleboards. According to Halabe et al. (1997), materials exhibit elastic behaviour when a force is applied for a very short duration and behave as a viscous liquid when a force is applied for longer time. As static bending test takes long duration compared to the TOF or resonance test, higher moduli of elasticity are obtained by the later methods. $M O E_{\text {stat }}$ represents a local stiffness while the $M O E_{d y n}$ represents a mean value over the full specimen. Overall, $M O E_{d y n}$ was found to be the highest when Fakopp Ultrasonic Timer was used, and it was about $11 \%$ and $16 \%$ higher respectively than $M O E_{d y n}$ obtained by BING and Sylvatest TRIO. The considered layer for the measurements might explain the difference between the two ultrasonic TOF methods (Fakopp Ultrasonic Timer, Sylvatest TRIO) on a three-layered particleboard, which is not characteristic and does not represent the whole section (Dunlop 1980). Low-density middle layers have the greatest effect on sound propagation time. A sound wave needs more time to travel across a low-density middle layer, and thus provides different results than the surface layers of higher density. In this contrast, Fakopp Ultrasonic Timer sound velocity results were the average of measurements done on both surfaces of the particleboards whilst an average of three layers (two faces and core layer) was used for Sylvatest TRIO. The addition of the low-density core layer into the final average in Sylvatest TRIO might explain the differences noted between the two ultrasonic testing methods. However, the prediction of $M O E_{\text {stat }}$ from $M O E_{d y n}$ values depends on the good correlation between them. Barbu et al. (2014) showed strong correlations between the density of the surface layer and the $M O E_{\text {stat }}$ and $M O R_{\text {stat }}$ for particleboards and medium density fibreboards (MDF). Sound velocity in the panel direction is dominated by the surface layers with higher densities and mainly influence $M O E_{\text {stat }}$ and $M O R_{\text {stat }}$ (Kruse 1997) whilst the porous core layer influences sound velocity perpendicular to the panel surface (Hilbers et al. 2009). However, both methods tested here were able to capture the structural differences among the particleboards types. As for example, the high-density particleboard (PB2) gave the highest values.

Linear regression analysis was employed to determine how well a particular acoustic method could predict the $M O E_{\text {stat }}$ or $M O R_{\text {stat }}$ values by the $M O E_{d y n}$ values on samples with different directions (parallel and perpendicular) and EMC levels (Tab. 7). Significant positive relationships (confidence level of 0.05) were found between $M O E_{d y n}$ and $M O E_{\text {stat }}$ for samples in the parallel and perpendicular production directions acclimatized in different humid conditions. This result is in well agreement with a previous study (Han et al. 2006). The coefficients of determination $\left(\mathrm{R}^{2}\right)$ ranged from 0.889 to 0.995 for the different acoustic methods. All three methods, Fakopp 
Vol. 65 (3): 2020

Ultrasonic Timer, BING and Sylvatest TRIO, performed well to predict $M O E_{\text {stat }}$. Linear regression models between $M O R_{\text {stat }}$ and MORdyn also showed positive relationships. Those developed regression models were found statistically significant at the 0.05 confidence level for most of the relationships on samples at different relative humidity levels. The coefficients of determination $\left(\mathrm{R}^{2}\right)$ ranged from 0.852 to 0.994 . Sylvatest TRIO performed better than the other two methods in predicting $M O R_{\text {stat }}$.

Tab. 7: Regression analysis results on the relationships between static moduli of elasticity ( $M O E_{\text {stat }}$ ) and rupture $\left(M O R_{\text {stat }}\right)$, and dynamic modulus of elasticity $\left(M O E_{\text {dyn }}\right)$. Model: $M O E_{\text {stat }}$ or $M O R_{\text {stat }}=$ Intercept + Slope $\times M O E_{\text {dyn }}$.

\begin{tabular}{|c|c|c|c|c|c|c|c|c|c|}
\hline \multirow{2}{*}{$\begin{array}{l}\text { Testing } \\
\text { method }\end{array}$} & \multirow{2}{*}{ RH (\%) } & \multicolumn{3}{|c|}{ Parallel direction } & \multirow{2}{*}{ p-value } & \multicolumn{3}{|c|}{ Perpendicular direction } & \multirow{2}{*}{ p-value } \\
\hline & & Intercept & Slope & $\mathrm{R}^{2}$ & & Intercept & Slope & $\mathrm{R}^{2}$ & \\
\hline \multicolumn{10}{|c|}{$M O R_{s t a t}-M O E_{d v n}$ relationship } \\
\hline BING & \multirow[t]{3}{*}{35} & 880.030 & 0.534 & 0.981 & $0.006^{*}$ & 282.620 & 0.661 & 0.992 & $0.004^{*}$ \\
\hline Fakopp & & 33.816 & 0.669 & 0.991 & $0.004^{*}$ & -306.220 & 0.753 & 0.978 & $0.011^{*}$ \\
\hline Sylvatest & & 163.850 & 0.766 & 0.888 & $0.058 \mathrm{~ns}$ & -237.760 & 0.863 & 0.945 & $0.028^{*}$ \\
\hline BING & \multirow[t]{3}{*}{65} & 749.930 & 0.511 & 0.960 & $0.020^{*}$ & 291.790 & 0.608 & 0.991 & $0.005^{*}$ \\
\hline Fakopp & & 26.165 & 0.621 & 0.988 & $0.006^{*}$ & 42.640 & 0.610 & 0.986 & $0.007^{*}$ \\
\hline Sylvatest & & 196.120 & 0.674 & 0.995 & $0.002^{*}$ & -72.960 & 0.728 & 0.975 & $0.013^{*}$ \\
\hline BING & \multirow[t]{3}{*}{85} & 587.210 & 0.501 & 0.970 & $0.015^{*}$ & 152.600 & 0.618 & 0.961 & $0.019^{*}$ \\
\hline Fakopp & & 88.143 & 0.561 & 0.981 & $0.010^{*}$ & -337.180 & 0.669 & 0.971 & $0.015^{*}$ \\
\hline Sylvatest & & 130.090 & 0.625 & 0.988 & $0.006^{*}$ & -240.300 & 0.721 & 0.962 & $0.019^{*}$ \\
\hline \multicolumn{10}{|c|}{$M O R_{\text {stat }}-M O E_{d y n}$ relationship } \\
\hline BING & \multirow[t]{3}{*}{35} & 1.148 & 0.003 & 0.869 & $0.068 \mathrm{~ns}$ & 0.454 & 0.036 & 0.875 & $0.064 \mathrm{~ns}$ \\
\hline Fakopp & & -4.202 & 0.004 & 0.899 & $0.052 \mathrm{~ns}$ & -3.185 & 0.004 & 0.912 & $0.045^{*}$ \\
\hline Sylvatest & & -5.425 & 0.005 & 0.996 & $0.002^{*}$ & -3.322 & 0.005 & 0.935 & $0.032 *$ \\
\hline BING & \multirow[t]{3}{*}{65} & 1.345 & 0.003 & 0.852 & $0.077 \mathrm{~ns}$ & 0.160 & 0.004 & 0.894 & $0.055 \mathrm{~ns}$ \\
\hline Fakopp & & -3.442 & 0.004 & 0.886 & $0.059 \mathrm{~ns}$ & -1.893 & 0.004 & 0.959 & $0.021^{*}$ \\
\hline Sylvatest & & -2.959 & 0.005 & 0.961 & $0.020^{*}$ & -2.594 & 0.005 & 0.946 & $0.027^{*}$ \\
\hline BING & \multirow[t]{3}{*}{85} & -1.198 & 0.004 & 0.950 & $0.026^{*}$ & -1.906 & 0.004 & 0.958 & $0.021^{*}$ \\
\hline Fakopp & & -5.223 & 0.005 & 0.952 & $0.024^{*}$ & -5.473 & 0.005 & 0.974 & $0.013^{*}$ \\
\hline Sylvatest & & -5.181 & 0.005 & 0.994 & $0.003^{*}$ & -4.873 & 0.005 & 0.978 & $0.011^{*}$ \\
\hline
\end{tabular}

* Significant regression equation at the 0.05 level (two-tailed); ns- non significant regression equation; $\mathrm{R}^{2}$ - coefficient of determination.

Previous studies (Liang and Fu 2007, Chauhan and Sethy 2016) showed better relationships of $M O E_{\text {stat }}$ and $M O E_{d y n}$ when $M O E_{d y n}$ was measured with resonance frequency by the Fast Fourier Transform (FFT) technique than with the TOF techniques (ultrasonic, stress wave). This is because the resonance speed by the vibration method is the function of the volume weighted average stiffness of the entire sample whilst in TOF methods, the high frequency waves travels at a relatively faster speed in stiffer and denser material (Chauhan et al. 2005). However, for particleboard, notifiable differences among the tested methods were not observed. In addition, this study showed that the differences in $M O E_{d y n}$ measured by any of these three methods was not constant over the entire $M O E_{\text {stat }}$ or $M O R_{\text {stat }}$ range. The slope of the equations relating $M O E_{d y n}$ to $M O E_{\text {stat }}$ or $M O R_{\text {stat }}$ was different in all three cases and was the lowest in BING and the highest in Sylvatest TRIO, which is in agreement with Chauhan and Sethy (2016). Previous studies (Bos 
and Casagrande 2003, Hassan et al. 2013) showed that the correlation coefficients between the $M O E_{d y n}$ and $M O E_{\text {stat }}$ are higher than those between the $M O E_{d y n}$ and $M O R_{\text {stat }}$. This fact was also observed in the current study.

\section{CONCLUSIONS}

This study investigated the potential for predicting the bending properties of different particleboard types by using resonance and time-of-flight methods at three different humid conditions (dry, standard and wet). The overall conclusions of the study are given below:

(1) Both $M O E_{\text {stat }}$ and $M O R_{\text {stat }}$ decreased with increases in particleboards' moisture content. Bending properties increased with the density of the particleboards. Linear relationships were found between both $M O E_{\text {stat }}$ and $M O R_{\text {stat }}$ with density for every humid condition.

(2) At a given humid condition, higher $M O E_{\text {stat }}$ and $M O R_{\text {stat }}$ values were observed in samples parallel compared to samples perpendicular to the production line. Overall, samples parallel to production line had $M O E_{\text {stat }}$ and $M O R_{\text {stat }}$ respectively $12 \%$ and $8 \%$ higher than the samples perpendicular to the production line.

(3) Positive linear relationships were found between $M O E_{\text {stat }}$ and $M O R_{\text {stat }}$ at dry $\left(\mathrm{R}^{2}=0.83\right)$, standard $\left(\mathrm{R}^{2}=0.90\right)$ and wet $\left(\mathrm{R}^{2}=0.93\right)$ conditions.

(4) All three methods (BING, Fakopp Ultrasonic Timer and Sylvatest TRIO) showed higher $M O E_{d y n}$ values in samples parallel than in samples perpendicular to the production line. $M O E_{d y n}$ of particleboards decreased as their moisture content increased, and was statistically significant lower at the wet than at the dry condition.

(5) The mean values of $M O E_{d y n}$ were higher than $M O E_{\text {stat }}$ for each particleboard type and humid condition. Overall, $M O E_{d y n}$ was found $29 \%, 37 \%$ and $27 \%$ higher than $M O E_{\text {stat }}$ when BING, Fakopp Ultrasonic Timer Sylvatest TRIO were used respectively.

(6) The obtained strong and statistically significant $M O E_{s t a t}-M O E_{d y n}$ and $M O R_{\text {stat }}-M O E_{d y n}$ linear relationships at almost every humid condition and production direction suggested that the resonance and TOF methods could be useful in practical quality control for predicting the static bending properties of particleboards. All tools showed exceptional ability to predict $M O E_{\text {stat }}$ while Sylvatest TRIO provided better $M O R_{\text {stat }}$ prediction results than Fakopp Ultrasonic Timer and BING.

\section{ACKNOWLEDGEMENTS}

The authors acknowledge financial support from the Kamprad Family Foundation for the project "Sustainable use of virgin and recovered raw material streams for innovative bio-based products and business stimulation in Southern Sweden (project ID: 20160052)".

\section{REFERENCES}

1. Akitsu, H., Norimoto, M., Morooka, T., Rowell, R.M., 1993: Effect of humidity on vibrational properties of chemically modified wood. Wood and Fiber Science 25(3): 250-260. 
2. Amishev, D., Murphy, G.E., 2008: In-forest assessment of veneer grade douglas-fir logs based on acoustic measurement of wood stiffness. Forest Products Journal 58(11): 42-47.

3. Ayrilmis, N., Buyuksari, U., As, N., 2010: Bending strength and modulus of elasticity of wood-based panels at cold and moderate temperatures. Cold Regions Science and Technology 63(1-2): 40-43.

4. Baar, J., Tippner, J., Rademacher, P., 2015: Prediction of mechanical properties- modulus of rupture and modulus of elasticity- of five tropical species by nondestructive methods. Maderas. Ciencia y tecnología 17(2): 239-252.

5. Baltrušaitis, A., Mišeikytė S., 2011: Strength and stiffness properties of the lithuanian grown scots pine (Pinus sylvestris): non-destructive testing methods vs. static bending. Wood Research 56(2): 157-168.

6. Barbu, M.C., Hasener, J., Bernardy, G., 2014: Modern testing of wood-based panels, process control, and modelling. In: Research developments in wood engineering and technology (eds. Aguilera, A., Davim, J.P.). IGI Global, PA, USA, Pp 90-130.

7. Bekhta, P.; Marutzky, R. 2007. Bending strength and modulus of elasticity of particleboards at various temperatures. Holz als Roh- und Werkstoff 65(2): 163-165.

8. Benthien, J.T.; Ohlmeyer, M., 2018. Enhancement of low-density particleboard properties by core layer particle orientation. European Journal of Wood and Wood Products 76(3): 1087-1091.

9. Bodig, J., 2000: The process of NDE research for wood and wood composites. In: $12^{\text {th }}$ International symposium on nondestructive testing of wood, University of Western Hungary, Sopron, Pp 7-22.

10. Bos, F., Casagrande, S.B., 2003: On-line non-destructive evaluation and control of woodbased panels by vibration analysis. Journal of Sound and Vibration 268(2): 403-412.

11. Brancheriau, L., Baillères, H., 2002: Natural vibration analysis of clear wooden beams: a theoretical review. Wood Science and Technology 36(4): 347-365.

12. Brancheriau, L., Baillères, H., 2003: Use of the partial least squares method with acoustic vibration spectra as a new grading technique for structural timber. Holzforschung 57(6): 644-652.

13. Bucur, V., 2006: Acoustics of wood. 2nd ed. Springer Series in Wood Science, SpringerVerlag Berlin Heidelberg, Berlin, 393 pp.

14. Buyuksari, U., 2012. Physical and mechanical properties of particleboard laminated with thermally compressed veneer. BioResources 7(1): 1084-1091.

15. Chauhan, S., Sethy, A., 2016: Differences in dynamic modulus of elasticity determined by three vibration methods and their relationship with static modulus of elasticity. Maderas. Ciencia y tecnología 18(2): 373-382.

16. Chauhan, S.S., Entwistle, K.M., Walker, J.F.C., 2005: Differences in acoustic velocity by resonance and transit-time methods in an anisotropic laminated wood medium. Holzforschung 59(4): 428-434.

17. Dickson, R.L., Matheson, A.C., Joe, B., Ilic, J., Owen, J.V., 2004: Acoustic segregation of Pinus radiata logs for sawmilling. New Zealand Journal of Forestry Science 34(2): 175-189.

18. Dinwoodie, J.M., 1978: The properties and performance of particleboard adhesives. Journal of the Institute of Wood Science 8(2): 59-68.

19. Dunlop, J.I., 1980: Testing of particle board by acoustic techniques. Wood Science and Technology 14(1): 69-78.

20. Edlund, J., Lindström, H., Nilsson, F., Reale, M., 2006: Modulus of elasticity of Norway spruce saw logs vs structural lumber grade. Holz als Roh- und Werkstoff 64(4): 273-279. 
21. Gerhards, C.C., 1982: Effect of moisture content and temperature on the mechanical properties of wood: an analysis of immediate effects. Wood and Fiber 14(1): 4-36.

22. Guan, C., Zhang, H., Hunt, J.F., Yan, H., 2016: Determining shear modulus of thin wood composite materials using a cantilever beam vibration method. Construction and Building Materials 121: 285-289.

23. Guan, C., Zhang, H., Zhou, L., Wang, X., 2015: Dynamic determination of modulus of elasticity of full-size wood composite panels using a vibration method. Construction and Building Materials 100: 201-206.

24. Halabe, U.B., Bidigalu, G.M., GangaRao, H.V.S., Ross, R.J., 1997: Nondestructive evaluation of green wood using stress wave and transverse vibration techniques. Materials Evaluation 55(9): 1013-1018.

25. Halligan, A.F., Schniewind, A.P., 1974: Prediction of particleboard mechanical properties at various moisture contents. Wood Science and Technology 8(1): 68-78.

26. Han, G., Wu, Q., Wang, X., 2006: Stress-wave velocity of wood-based panels: Effect of moisture, product type, and material direction. Forest Products Journal 56(1): 28-33.

27. Hassan, K.T.S., Horáček, P., Tippner, J., 2013: Evaluation of stiffness and strength of scots pine wood using resonance frequency and ultrasonic techniques. BioResources 8(2): 1634-1645.

28. Hein, P.R.G., Lima, J.T., Gril, J., Rosado, A.M., Brancheriau, L., 2012: Resonance of scantlings indicates the stiffness even of small specimens of Eucalyptus from plantations. Wood Science and Technology 46(4): 621-635.

29. Hilbers, U., Thoemen, H., Barbu, M.C., Hasener, J., 2009: Ultrasonic inspection of wood composites: How process parameters influence the transmission signal. In: Proceeding of 43rd International Wood Composites Symposium, Academic Press, Seattle, USA, Pp 614-624.

30. Jang, S.S., 2000: Evaluation of lumber properties by applying stress waves to larch logs grown in Korea. Forest Products Journal 50(3): 44-48.

31. Jian, J., Lu, X., 2017: Effect of blocked polyurethane prepolymer on properties of MUFparticleboard made from high moisture particles. International Journal of Adhesion and Adhesives 78: 189-194.

32. Kollmann, F.F.P., Kuenzi, E.W., Stamm, A.J., 1975: Principles of wood science and technology- II wood based materials. Springer-Verlag, Berlin Heidelberg New York, 703 pp.

33. Kruse, K., 1997: Modern techniques for efficient process control of wood-based panel production. In: Proceedings of workshop on non-destructive testing of panel products. Academic Press, Llandudno, Wales, Pp 1-9.

34. Legg, M., Bradley, S., 2016: Measurement of stiffness of standing trees and felled logs using acoustics: A review. The Journal of the Acoustical Society of America 139(2): 588-604.

35. Liang, S.-Q. Fu, F., 2007: Comparative study on the three dynamic modulus of elasticity and static modulus of elasticity for Lodgepole pine lumber. Journal of Forestry Research 18(4): 309-312

36. Lindström, H., Reale, M., Grekin, M., 2009: Using non-destructive testing to assess modulus of elasticity of Pinus sylvestris trees. Scandinavian Journal of Forest Research 24(3): 247-257.

37. Llana, D.F., Iñiguez-Gonzalez, G, Arriaga, F., P. Niemz, P. 2014: Influence of temperature and moisture content on non-destructive measurements in Scots pine wood. Wood Research 59(5): 769-780. 
38. Matheson, A.C., Dickson, R.L., Spencer, D.J., Joe, B., Ilic, J., 2002: Acoustic segregation of Pinus radiata logs according to stiffness. Annals of Forest Science 59(5-6): 471-477.

39. McNatt, J.D., Wellwood, R.W., Bach, L., 1990: Relationships between small-specimen and large panel bending tests on structural wood-based panels. Forest Products Journal 40(9): 10-16.

40. Niemz, P., Mannes, D., 2012: Non-destructive testing of wood and wood-based materials. Journal of Cultural Heritage 13S(3): S26-S34.

41. Oliver, J.F., 1981: Adhesion in cellulosic and wood-based composites. Plenum Press, New York, $261 \mathrm{pp}$.

42. Olsson, A., Oscarsson, J., Johansson, M., Källsner, B., 2012: Prediction of timber bending strength on basis of bending stiffness and material homogeneity assessed from dynamic excitation. Wood Science and Technology 46(4): 667-683.

43. Øvrum, A., 2013: In-forest assessment of timber stiffness in Norway spruce (Picea abies (L.) Karst.). European Journal of Wood and Wood Products 71(4): 429-435.

44. Pritchard, J., Ansell, M.P., Thompson, R.J.H., Bonfield, P.W., 2001: Effect of two relative humidity environments on the performance properties of MDF, OSB and chipboards. Wood Science and Technology 35(5): 395-423.

45. Rachtanapun, P., Sattayarak, T., Ketsamak, N., 2012: Correlation of density and properties of particleboard from coffee waste with urea-formaldehyde and polymeric methylene diphenyl diisocyanates. Journal of Composite Material 46(15): 1839-1850.

46. Ross, R.J., Pellerin, R.F., 1988: NDE of wood-based composites with longitudinal stress waves. Forest Products Journal 38(5): 39-45.

47. SS-EN 310, 1993: Wood-based panels- determination of modulus of elasticity in bending and of bending strength.

48. SS-EN 322, 1993: Wood-based panels- determination of moisture content.

49. SS-EN 323, 1993: Wood-based panels- determination of density.

50. Tsehaye, A., Buchanan, A.H., Walker, J.C.F., 2000a: Selecting trees for structural timber. Holz als Roh- und Werkstoff 58(3): 162-167.

51. Tsehaye, A., Buchanan, A.H., Walker, J.C.F., 2000b: Sorting of logs using acoustics. Wood Science and Technology 34(4): 337-344.

52. Wang, X., 2013: Acoustic measurements on trees and logs: a review and analysis. Wood Science and Technology 47(5): 965-975.

53. Wong, E.D., Zhang, M., Wang, Q. Kawai, S., 1998: Effects of mat moisture content and press closing speed on the formation of density profile and properties of particleboard. Journal of Wood Science 44(4): 287-295.

54. Wu, Q., Piao, C., 1999: Thickness swelling and its relationship to internal bond strength loss of commercial oriented strandboard. Forest Products Journal 49(7/8): 50-55.

55. Wu, Q. Suchsland, O., 1997: Effect of moisture on the flexural properties of commercial oriented strandboards. Wood and Fiber Science 29(1): 47-57. 
Sheikh Ali Ahmed, Stergios Adamopoulos*, Francesco Poggi

Linnaeus University

Faculty of Technology

Department of Forestry and Wood Technology

Georg Lückligs Plats I

35 I 95 VÄXjö

SwEDEN

*Corresponding author: stergios.adamopoulos@1nu.se

Thomas Walther

IKEA Industry AB

MaLmö

SwEDEN 